\title{
Beach Topography Surveying Using Unmanned Aerial Vehicle Photogrammetry Technology
}

Hui-Ming Fang

Bachelor Degree Program in Ocean Engineering and Technology, National Taiwan Ocean University, Taiwan

Kuan-Tsung Chang

Department of Civil Engineering and Environmental Informatics, Minghsin University of Science and Technology, Taiwan

Sung-Shan Hsiao

Department of Harbor and River Engineering, National Taiwan Ocean University, Center of Excellence for Ocean Engineering, Taiwan, sshsiao@mail.ntou.edu.tw

Shih-Peng Chiang

Department of Harbor and River Engineering, National Taiwan Ocean University, Taiwan

Follow this and additional works at: https://jmstt.ntou.edu.tw/journal

Part of the Fresh Water Studies Commons, Marine Biology Commons, Ocean Engineering Commons, Oceanography Commons, and the Other Oceanography and Atmospheric Sciences and Meteorology Commons

\section{Recommended Citation}

Fang, Hui-Ming; Chang, Kuan-Tsung; Hsiao, Sung-Shan; and Chiang, Shih-Peng (2021) "Beach Topography Surveying Using Unmanned Aerial Vehicle Photogrammetry Technology," Journal of Marine Science and Technology. Vol. 29:

Iss. 1, Article 1.

DOI: $10.51400 / 2709-6998.1000$

Available at: https://jmstt.ntou.edu.tw/journal/vol29/iss1/1

This Research Article is brought to you for free and open access by Journal of Marine Science and Technology. It has been accepted for inclusion in Journal of Marine Science and Technology by an authorized editor of Journal of Marine Science and Technology. 


\title{
Beach Topography Surveying Using Unmanned Aerial Vehicle Photogrammetry Technology
}

\author{
Hui-Ming Fang ${ }^{a}$, Kuan-Tsung Chang ${ }^{b}$, Sung-Shan Hsiao ${ }^{c}$, , Shih-Peng Chiang ${ }^{d}$ \\ ${ }^{a}$ Bachelor Degree Program in Ocean Engineering and Technology, National Taiwan Ocean University, Taiwan \\ ${ }^{\mathrm{b}}$ Department of Civil Engineering and Environmental Informatics, Minghsin University of Science and Technology, Taiwan \\ ${ }^{c}$ Department of Harbor and River Engineering, National Taiwan Ocean University, Center of Excellence for Ocean Engineering, Taiwan \\ d Department of Harbor and River Engineering, National Taiwan Ocean University, Taiwan
}

\begin{abstract}
The mechanisms of in situ topography changes must be identified for spatial planning in coastal areas. In this study, the authors used in situ direct measurement methods and indirect remote-sensing technologies to develop a method for beach topography surveillance. Unmanned aerial vehicles (UAVs) have advantages of high portability and mobility and low operating altitude. Therefore, a UAV was equipped with a lightweight camera and a positioning system that comprised a global positioning system and an inertial measurement unit. Aerial photogrammetry and aerial triangulation methods were adopted for matching image feature points to obtain the corresponding topographic points in the sand. A virtual base station with real-time kinematic positioning functionality was used to measure the coordinates of the ground control points for correcting the actual coordinates to obtain actual topographic points of the beach sand. The results obtained using image-matching point clouds and direct measurements were compared. The ground sample distance of a UAV at the operational altitude of $70 \mathrm{~m}$ was $3.26 \mathrm{~cm}$. Moreover, the average elevation error was $3.20 \mathrm{~cm}$, and the root mean square error was $0.169 \mathrm{~m}$. The measurement error was $\pm 25 \mathrm{~cm}$, which was within the acceptance criteria of $\pm 50 \mathrm{~cm}$ set by Water Resources Agency, Ministry of Economic Affairs, Taiwan. UAV imaging technology can increase the efficiency of conventional manual sampling and reduce the cost of indirect observations, thus minimizing the measurement errors and field measurement costs.
\end{abstract}

Keywords: Unmanned aerial vehicles, Photogrammetry, Beach topography

\section{Introduction}

$\mathrm{T}$ aiwan is surrounded by oceans. Conducting anthropogenic development either for coastal development or marine protection will eventually create problems related to coastal conservation. The increasing volume of discussions on global climate change has gradually attracted public attention toward coastal conservation. Thus, one should be able to adequately comprehend the mechanism of changes in coastal topography changes to implement coastal conservation. Topographic survey methods used for monitoring topographic changes can be categorized into direct and indirect methods, namely in situ observation and remote-sensing methods, respectively. Specifically, most in situ observations to monitor the changes in the topography of a region are conducted using conventional topographic mapping techniques and auxiliary methods, such as Global Navigation Satellite System receivers or a Total Station (TS). In remote sensing, data related to objects, regions, or phenomena can be obtained without physical contact with the measured target. Short-term periodic surveys conducted during conventional beach 
topographic surveys require tremendous amounts of human resources and funds. Moreover, such surveys may not effectively provide information related to temporal topographic changes.

Because of various advancements in video surveillance technology, real-time image monitoring systems have become optimal tools for monitoring and managing local coastal areas in advanced countries. Beach topography and coastal conditions can be monitored at any time by using a typical realtime image monitoring system. Coastline landform patterns recorded by the system can be extracted using image processing technology, and these patterns can be used for analyzing the short-, medium-, and long-term changes in coastal topography. Currently, video imagery is typically used in ocean physics studies. Many scholars have used video imagery to monitor coastal topography. For instance, breaking waves exhibit maximal brightness at the beach line, and thus, images of breaking waves captured using a single camera can be used to plot the contour map of an intertidal zone [8,15]. The Argus video monitoring system [9] was adopted to monitor near-shore beach line topography by using images captured with a charge-coupled device. To monitor and analyze coastal images, three observation stations were established to collect data for correcting the direct linear transformation formula of the Argus system [10].

For a few occasions, such as the occurrence of specific meteorological events or considerable topographic changes detected by an in situ auxiliary monitoring system, horizontal change may be inadequate to effectively provide detailed information about the event in question. Advances in photogrammetry software and hardware have increased the utility of motion- and feature-based image-matching techniques, and these can be used to acquire stereoscopic images. Moreover, users need not be in contact with the target object during the image-acquisition process. Thus, the imageacquisition process is not restricted by environmental conditions. For example, a study combined multi-view stereopsis technology, photogrammetry, and computer vision to generate point clouds of a shingle beach in southeast Tasmania, Australia. The accuracy of the method was compared with those of the real-time kinematic dual-frequency differential global positioning system (RTK-DGPS) and TS survey [7]. Researchers have used virtual reference stations and terrestrial laser scanning technology to compare the accuracies of different structure-frommotion point clouds [6]. Binocular stereo imaging was applied to image processing for reconstructing three-dimensional (3D) topographies. Moreover, laser spots were used to resolve the problem of homogenous color levels on beaches [5]. Researchers have employed unmanned aerial vehicles (UAVs) to capture aerial photographs of a topography before and after a meteorological event and have compared the maximum wave run-up data obtained from UAV imagery, numerical models, and light detection and ranging (LIDAR) surveys $[1,2]$. Moreover, researchers have compared the survey results of a RTK-GPS mounted on a mobile mapping vehicle and repeated UAV aerial photography measurements $[4,12]$.

UAV imagery technology is employed in this study (this study continued the author's research [3], using UAV imagery technology) to solve the problem of low efficiency associated with the conventional manual sampling technique, reduce the instrument costs of remote-sensing technology and field surveying, and reduce the number of measurement errors. UAVs have several advantages, such as high portability and mobility and low operational altitude. The UAV used in the present study carried the following devices: a lightweight sensor system equipped with a position and orientation system, a GPS receiver, and an inertial measurement unit (IMU). The feature points of multiview image pairs are matched in this study to obtain $3 \mathrm{D}$ positions in a beach area by using imagematching technology and aerial triangulation adjustment. Moreover, a virtual base station employing real-time kinematic (RTK) positioning (VBS-RTK) is used to measure the actual coordinates of ground control points (GCPs) and those of check points. These coordinates are used to correct the results pertaining to the obtained sand topography and determine the differences between image-matching point clouds and direct measurement data. Of them, the images captured by the UAV in this study were in accordance with the water level $(0 \mathrm{~m})$ of the area. Through consistent photographs, the images acquired using a UAVmounted non-metric camera can be imported into the software environment of Pix4Dmapper to obtain orthorectified images, digital surface models (DSMs), and digital elevation model of a test area.

\section{UAV photogrammetry accuracy verification}

\subsection{Setting GCPS}

Aerial photogrammetry technique users must verify the essential parameters that influence the results of aerial triangulation before conducting 


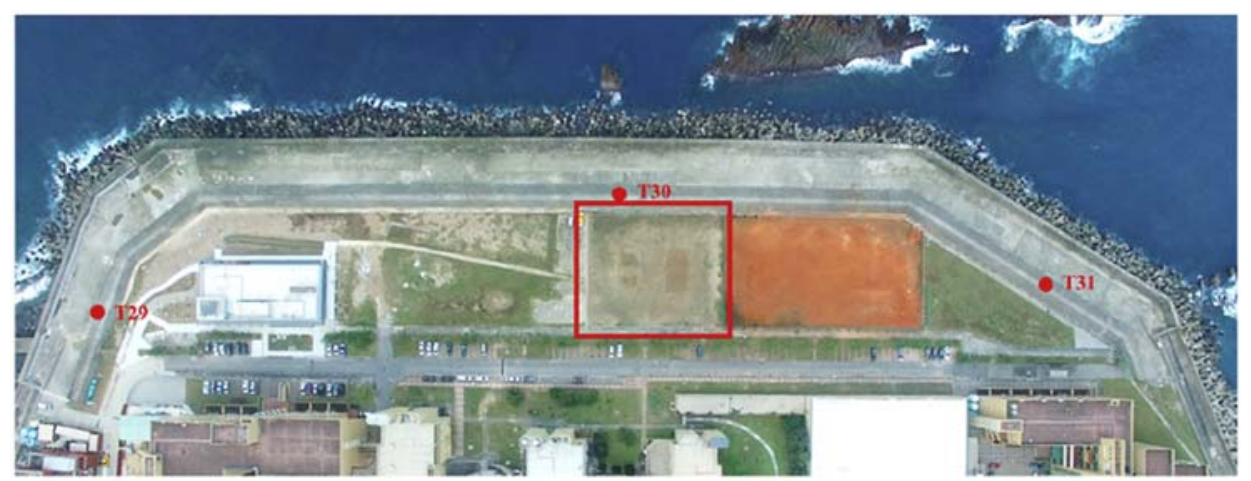

Fig. 1. Reference control points in experimental area.

UAV aerial photography to obtain accurate topographic data. These parameters, such as accuracy, form, GCP distribution, interior orientation, and camera imperfections, substantially influence the position correction of image points. Parameters, such as planar and vertical control measurement, GCP forms, and GCP distribution, should be planned according to the actual beach topography before conducting UAV imaging for beach topography mapping. The GCP distribution should meet the adjustment requirements of aerial triangulation. Specifically, the aerial photographs covering the GCPs of an area can be used to improve the computational reliability and accuracy of aerial triangulation adjustment [11]. To verify the accuracy of UAV surveys of beach topography, a flat and nonobstacle beach volleyball court in the National Taiwan Ocean University campus was selected as the test area. Three control points numbered T29, T30, and T31 built by the 10th River Management Office, Water Resources Agency, surrounding the test area can be used as reference points, shown as Fig. 1. In Fig. 1, the test area is denoted by the rectangular area marked with red lines. To verify the reliability of the given coordinates of the three reference points, a VBS-RTK positioning method was used to measure and calibrate the control system for UAV topographic surveying. Table 1 lists the coordinates measured using the VBS-RTK method and those of the three reference points. The distance residual between the baselines consisting of two reference points reached $0.5-2.0 \mathrm{~cm}$, and the

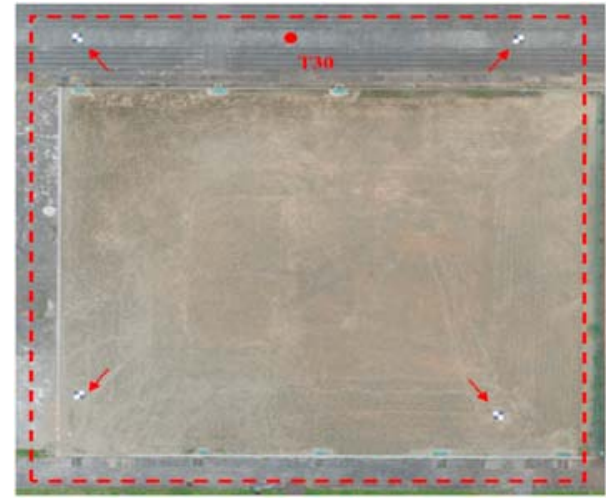

Fig. 2. Distribution of GCPs in beach court area.

orientation residual between vector orientations calculated using the given coordinates and those measured using the VBS-RTK method was smaller than $5^{\prime \prime}$, as summarized in Table 2 . Thus, the validation results indicated that the aforementioned three reference points can be used to measure the coordinates of the GCPs and obtain a reference topographic result. Because GPS-assisted aerial triangulation can be performed during UAV surveying, only four artificial marks distributed in the corners of the test area and T30 were used as the GCPs in the subsequent UAV flights (see Fig. 2). The average differences between the given and corresponding measured coordinates of the reference points can be regarded as systematic offsets to correct the VBS-RTK-measured coordinates of the

Table 1. VBS-RTK-measured coordinates of reference points

\begin{tabular}{|c|c|c|c|c|c|c|}
\hline \multirow[t]{2}{*}{ Control point \# } & \multicolumn{3}{|c|}{ Given coordinates } & \multicolumn{3}{|c|}{ Measured coordinates } \\
\hline & $\mathrm{N}$ & $\mathrm{E}$ & $\mathrm{Z}$ & $\mathrm{N}$ & $\mathrm{E}$ & $\mathrm{Z}$ \\
\hline $\mathrm{T} 29$ & 2782788.768 & 328606.762 & 7.674 & 2782788.528 & 328607.338 & 10.015 \\
\hline T30 & 2782763.035 & 328810.436 & 7.608 & 2782762.792 & 328811.026 & 9.970 \\
\hline $\mathrm{T} 31$ & 2782653.960 & 328962.835 & 7.651 & 2782653.718 & 328963.432 & 10.029 \\
\hline
\end{tabular}


Table 2. Accuracy validation of reference control points

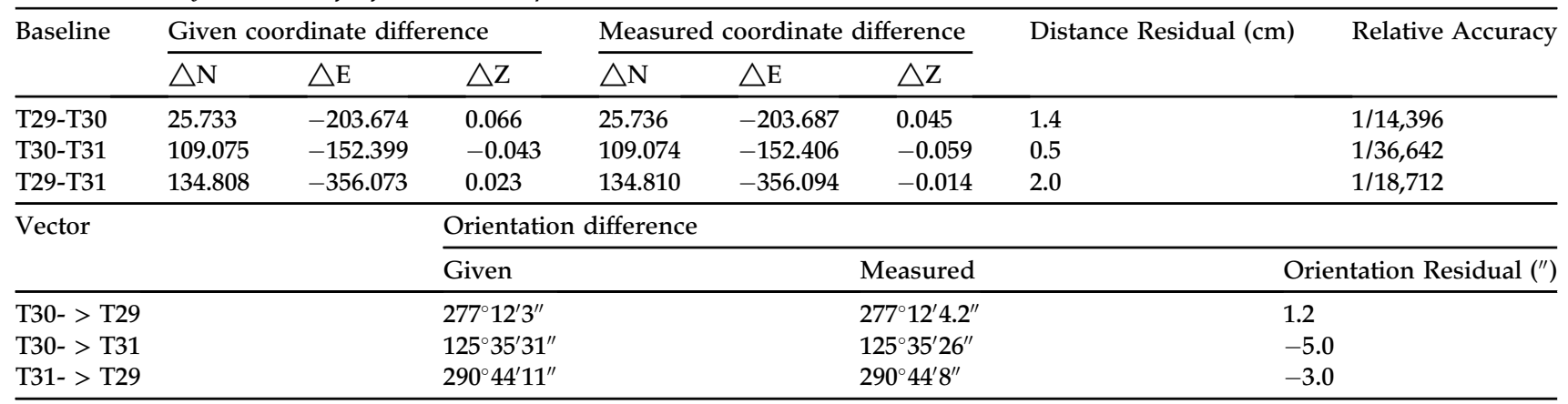

GCPs in a small test area. The results of this study suggest that when using the VBS-RTK to perform control measurements in UAV surveying, at least three satellite control points and one first-order benchmark should be used as references for coordinate transformation.

\subsection{Flight planning}

To meet the requirements of direct geo-referencing, aerial photography was conducted with a video camera drone (DJI Phantom 3 pro) equipped with a GPS module and an IMU. However, the accuracy of the GPS module and IMU was inadequate. Therefore, GPS-assisted aerial triangulation was employed [16]. Aerial photogrammetry is more suitable for a rectangular and open survey area. However, beach topography is a narrow terrain. Moreover, finding feature points for image matching is relatively difficult in a homogeneously sandy area $[5,13]$. Imagery overlap was arranged using the settings of the end lap (also called front overlap) and the side lap (Fig. 3). The mathematical relationship among the parameters of the end and side laps can be determined using Equations (1) and (2), respectively. The imagery front overlap ratio (left and right images) should be higher than $60 \%$ according to the mapping standard [14]. The accuracy of topographic map is a function of the ground sample distance (GSD) and the operational altitude (also called fly height above ground level (AGL)). The proportional relationship between the AGL and the GSD can be derived using Equation (3) as a function of the resolution of the photosensitive element. The GSD should not be longer than $10 \mathrm{~cm}$ according to the mapping standard for 1/1000 topographic maps. The double-S-type flying course was adopted in this study to increase the success rate of image matching (Fig. 4). Although this caused some disadvantages, such as long flight time, numerous images were obtained from different angles. The course increased the overall overlap rate effectively to cover the measurement area and increased the observation redundancy [17]. All the flight parameters were set using the Pix4Dcapture application.

$P E=\left(\frac{G-B}{G}\right) \times 100 \%$

$P S=\left(\frac{G-W}{G}\right) \times 100 \%$

where $P E$ represents the end lap rate, $P S$ the side lap rate, $G$ the length covered by a single photo, $B$ the flying base length, and $W$ the route interval.

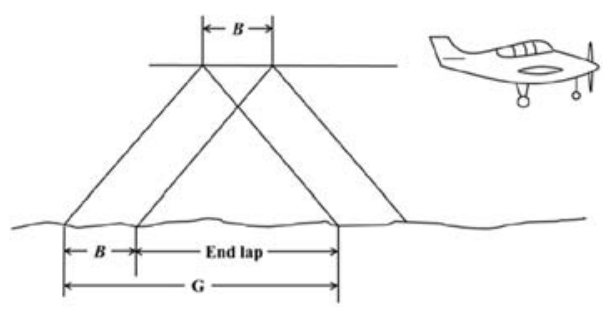

(a)

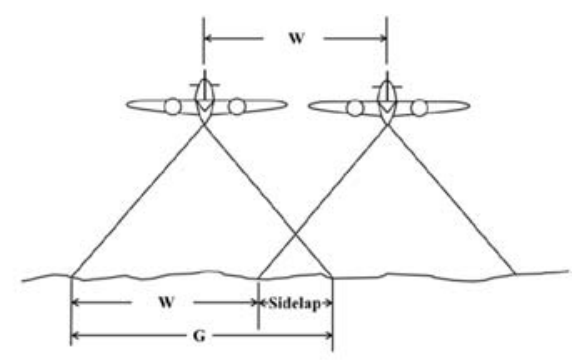

(b)

Fig. 3. Neighboring image overlaps: (a) End and (b) side laps. 


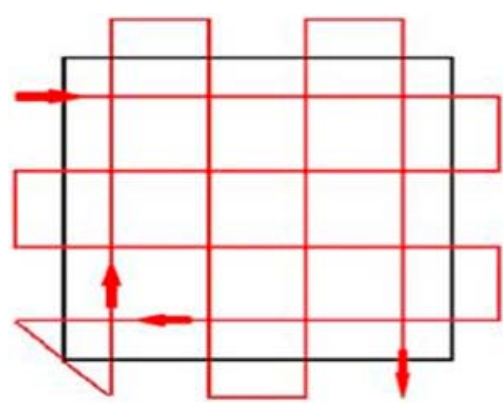

Fig. 4. Flight course used in this study.

$\frac{\text { Pixel Size }}{\text { Focal Length }}=\frac{G S D}{A G L}$

\section{Verification of observation accuracy}

The reference topography was obtained using a TS (LEICA 1205+). Then, UAV imaging flights were conducted based on the GCP coordinates obtained through VBS-RTK positioning. Finally, a 3D point cloud was derived using the UAV image postprocessing software application Pix4Dmapper. The corresponding elevations of the check points can be estimated using the 3D point clouds obtained through an inverse distance-weighted interpolation method. The topographical points used for the accuracy verification and the check points overlapping in the reference and measurement results are presented in Figs. 5 and 6, respectively. The elevation points were manually sampled based on the topographic changes in the test area, for example, the dense samples were obtained at the ladders with a fixed elevation difference in the right-upper side; therefore, it is not evenly distributed in Fig. 5. In Fig. 6, the red and blue points represent the elevation samples measured using the TS and the color mean values estimated using the Unmanned Aircraft Systems (AS)results, respectively. The

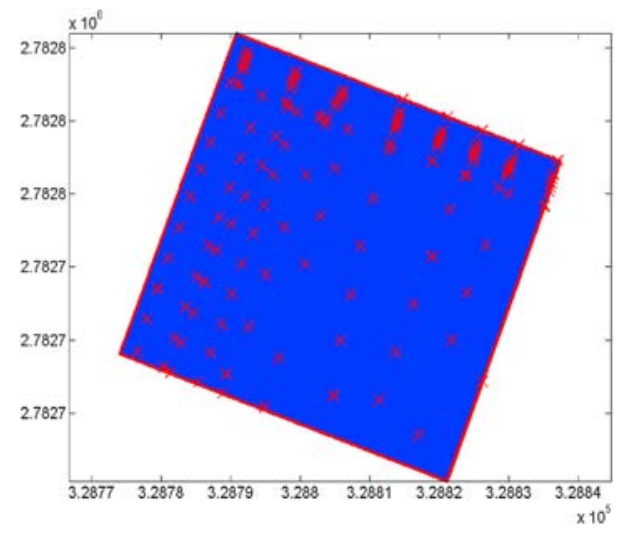

Fig. 5. Topographical points used for accuracy verification.

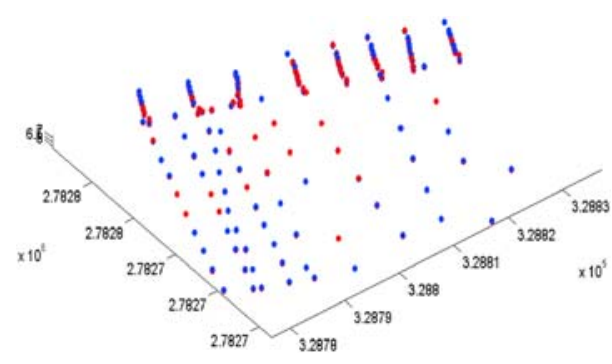

Fig. 6. Overlapping of 3D coordinates of check points.

appearance of red points indicates that the elevation values measured using the TS are larger than those estimated using the UAS results and vice versa. In Fig. 6, most of the points are blue, implying that the prism pole used in the TS survey sank into the sand surface during the survey. A reference topographic contour map and two sets of contour results obtained in two UAV flights at different altitudes are shown in Figs. 7-9. The elevation statistic of the reference topography was $5.75-7.33 \mathrm{~m}$, as in Fig. 7 . Moreover, the corresponding elevation statistics measured in UAV flights at the operational altitudes of $70 \mathrm{~m}$ and $100 \mathrm{~m}$ were $5.84-7.38 \mathrm{~m}$ and $5.92-7.37 \mathrm{~m}$, respectively. The overall topographic elevation distribution measured by means of UAV imaging at the operation altitude of $70 \mathrm{~m}$ was more consistent with the elevation distribution of the reference topography than that measured at the operational altitude of $100 \mathrm{~m}$. Moreover, two scatter plots pertaining to the reference topography and the topographies measured with UAV photogrammetry at the two aforementioned operational altitudes are displayed in Fig. 10. The horizontal axis of Fig. 10 represents the elevation values of the check points obtained using UAV photogrammetry, and vertical axis represents the elevation values of the check points as obtained by means of TS measurement. The best-fit results in Fig. 10 indicate a right-skew

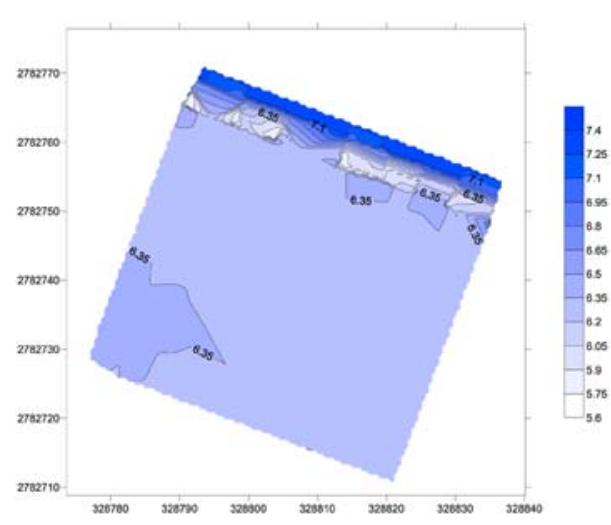

Fig. 7. Reference topographic contour map. 


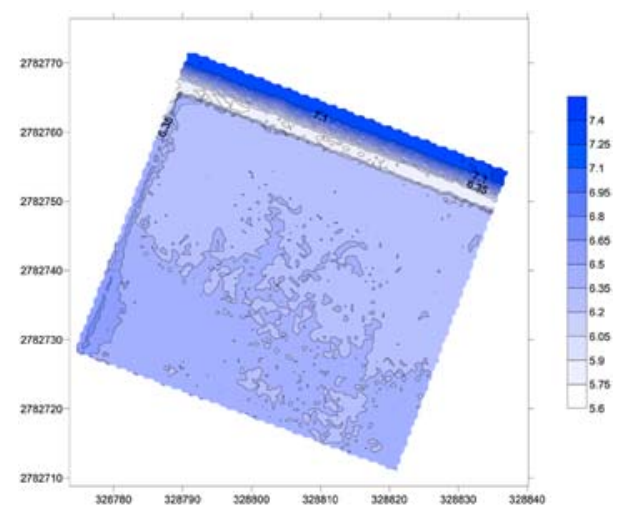

Fig. 8. Topographic contour map created using data obtained at the altitude of $70 \mathrm{~m}$.

trend in the two UAV topographies, meaning that the elevation values estimated using the UAV were larger than those measured using the TS. However, the topographic result obtained using the UAV at the operational altitude of $70 \mathrm{~m}$ (represented as Topo_UAV_70m) was more consistent with the results obtained using the TS (called as Topo_TS) than that obtained using the UAV at the operational altitude of $100 \mathrm{~m}$ (represented as Topo_UAV_100m). The maximum elevation errors of Topo_UAV_100m and Topo_UAV_70m were $\pm 40 \mathrm{~cm}$ and $\pm 30 \mathrm{~cm}$, respectively. The abovementioned check points were located at the ladders adjacent to the beach volleyball court. Moreover, at the elevations of $6.2-6.5 \mathrm{~m}$, good fits with the measurement results were mostly obtained in the sandy beach volleyball court area. A few accuracy indicators, namely mean

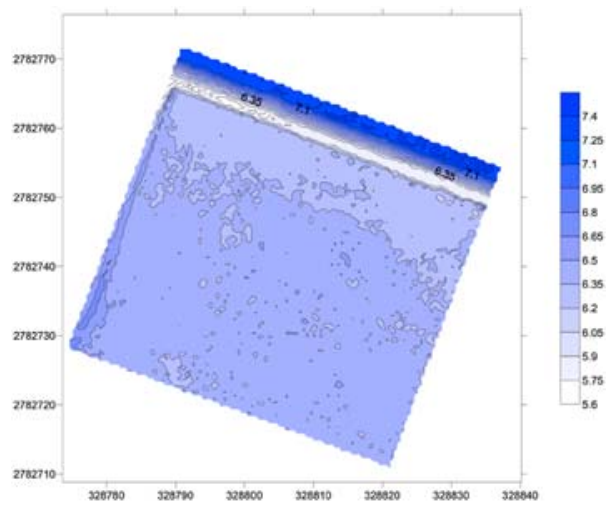

Fig. 9. Topographic contour map created using the data obtained at the altitude of $100 \mathrm{~m}$.

error, standard deviation, and root mean square error (RMSE), are listed in Table 3 to facilitate comparison of the results. The analytically obtained Pearson product-moment correlation coefficient between the Topo_TS result and the Topo_UAV_70m result was 0.936 while that between the Topo_TS result and the Topo_UAV_100m result was 0.931 . The results show a high level of correlation between the topographic results obtained using a TS system and those obtained using a UAV system at two flight altitudes. The acceptable tolerance regulated by the Water Resources Agency, Ministry of Economic Affairs, Taiwan, is $\pm 50 \mathrm{~cm}$. In this study, a stricter tolerance value of $\pm 25 \mathrm{~cm}$ was adopted for topographic elevation measurement, which complied with the topographic measurement regulations. This indicates that the proposed UAV image

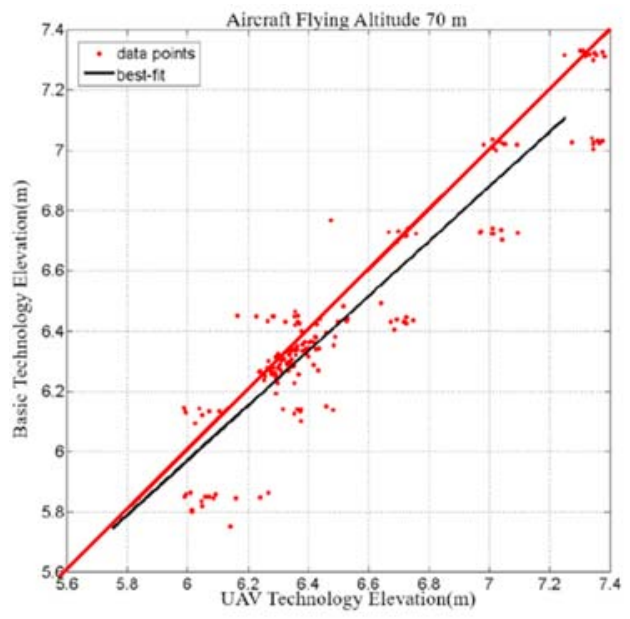

(a) $70 \mathrm{~m}$

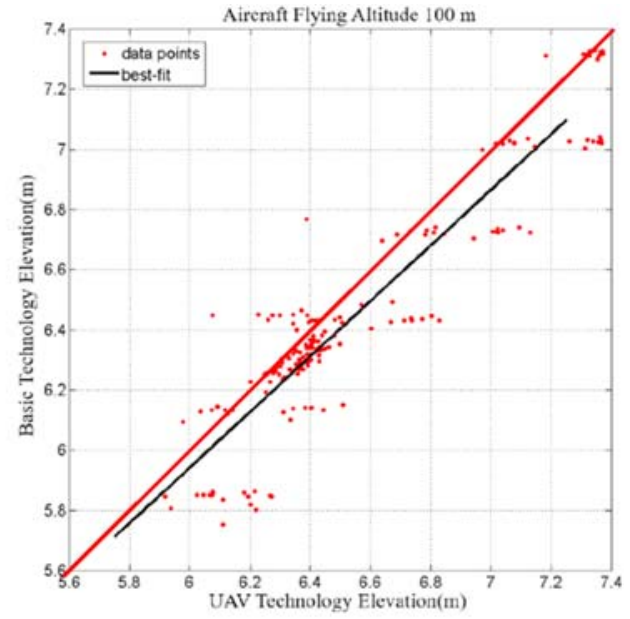

(b) $100 \mathrm{~m}$

Fig. 10. Scatter plots of the reference topography and the topography measured using UAV photogrammetry at two operational altitudes. 
Table 3. Elevation accuracy statistics for UAV results at two altitudes

\begin{tabular}{llll}
\hline Altitude $(\mathrm{m})$ & Mean error $(\mathrm{m})$ & Standard deviation $(\mathrm{m})$ & RMSE $(\mathrm{m})$ \\
\hline 70 & 0.077 & 0.140 & 0.159 \\
100 & 0.100 & 0.144 & 0.175 \\
\hline
\end{tabular}

measurement system can be used for beach topography measurement.

\section{Application example}

\subsection{Research area planning and configuration}

Yanliao Beach was selected as the study area for application of the UAV photogrammetry technique for the topographic mapping of a real beach (Fig. 11). Figure 12 illustrates the flying course and distribution of the GCPs in the study area obtained at different UAV operational altitudes by using the aforementioned UAV photogrammetry technique. The parameters settings used in two flight missions are displayed in the Table 4 . The camera angle in the Table represents the angle between the ground surface and the facing direction of camera, and near-vertical photography can be realized when the camera is set at an $80^{\circ}$ angle. Eleven full-control points were measured using VBS-RTK, and Pix4Dmapper, a postprocessing software application, was used to automatically produce orthophotos, DEM, and DSM based on user requests. The topographic point clouds measured using a UAV were obtained

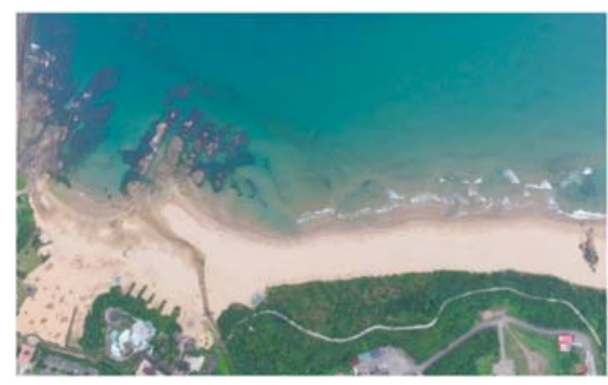

Fig. 11. Aerial view of Yanliao Beach.

through internal data processing and used to subsequently compare the measured and reference topographies.

\subsection{Comparison of results obtained using a TS}

The GSD values computed from the aerial images captured at the operational altitudes of $70 \mathrm{~m}$ and $100 \mathrm{~m}$ were 3.26 and $4.25 \mathrm{~cm}$, respectively. The sandy beach study area from land to shallow waters is displayed in Fig. 13(a). According to the imagematching properties, changes in dynamics at the junction between the sea and the land in the shallow water area will to lead ill-matched points founding (Fig. 13(b)). In general, image stitching or featurepoint matching is unsuitable for processing dynamic objects that change with time. A $0-m$ contour line (viewed as near-shoreline) was used as the

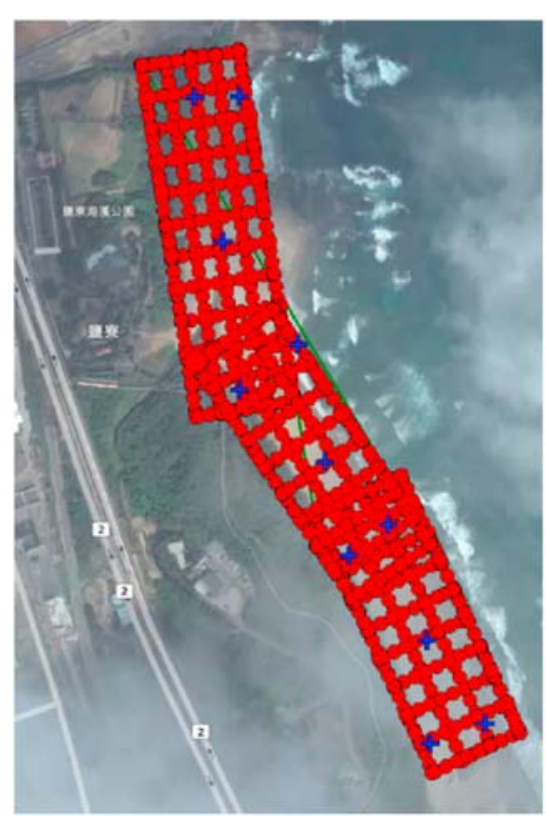

(a)

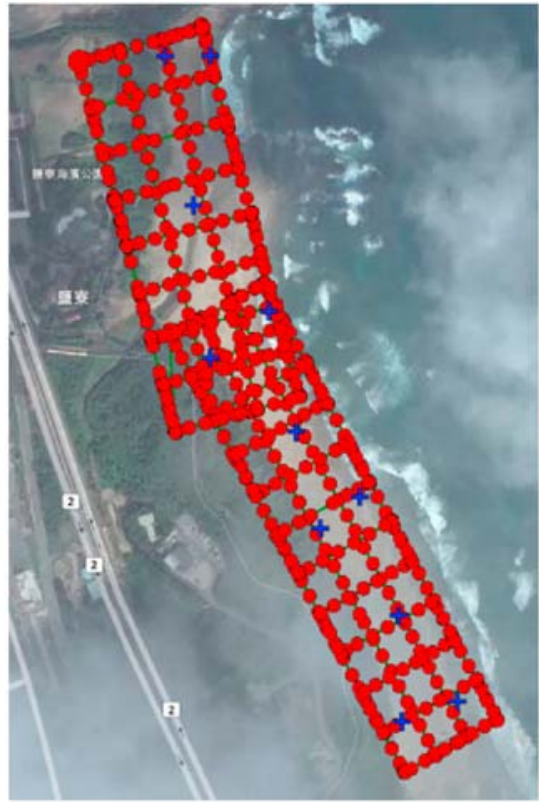

(b)

Fig. 12. Flight planning and layout of GCPs and flying courses on Yanliao Beach at the operational altitudes of (a) 70 and (b) $100 \mathrm{~m}$. 
Table 4. Flying course planning

\begin{tabular}{llc}
\hline Item & Flight settings & \\
\hline Altitude $(\mathrm{m})$ & 70 & 100 \\
Angle of the camera $(\mathrm{deg})$ & 80 & \\
Overlap rate $(\%)$ & End lap: 80\%; Side lap: \\
& $30 \%$ & \\
Route type & Double S & \\
No. of photos & 859 & 569 \\
Flight time (min) & 40 & 24 \\
\hline
\end{tabular}

*Flight conditions in clear weather and low tide.

land-sea boundary to facilitate the subsequent analysis for eliminating the influence of waves on the beach topography. Because the point number and density in the original image-matching point clouds were considerably higher than those in the reference topography (752 sample points) obtained using the TS, the elevation data of the UAV image point clouds, which had the same planar coordinates as those of the 752 reference points, were linearly interpolated using a weighted distance. A comparative analysis was conducted using the image overlaying technique (Fig. 14(a)). A reference contour map was generated by applying a Kriging function available in the software suite Surfer to the 752 points (Fig. 14(b)). The overall elevation distribution of the reference topography in the study area was approximately $0-5.55 \mathrm{~m}$. However, the elevation distribution obtained by applying the image-matching technique to the images obtained at the UAV operational altitude of $70 \mathrm{~m}$ was approximately -0.31 to $5.65 \mathrm{~m}$ (Fig. 15(a)). Moreover, the result obtained at the UAV operational altitude of $100 \mathrm{~m}$ was approximately -0.35 to $5.33 \mathrm{~m}$ (Fig. 15(b)). The differences in elevation distribution between the reference topography and the topographies obtained by means of UAV imaging at the two operational altitudes are displayed in Figs. 15(c) and (d), respectively.

A normal distribution of the elevation error between the reference topography and the topographies obtained through UAV imaging at two operational altitudes is presented in Fig. 16. The statistics of the four accuracy indicators, namely mean error $\mu$, standard deviation $\sigma$, RMSE, and allowable error, are summarized in Table 5. The mean error of the UAV image topography obtained at the operational altitude of $70 \mathrm{~m}$ was $0.032 \mathrm{~m}$, which was smaller than the error in the topography obtained at the altitude of $100 \mathrm{~m}$. Table 5 presents that the RMSEs at the operational altitudes of 70 and $100 \mathrm{~m}$ are 0.169 and $0.176 \mathrm{~m}$, respectively. Moreover,

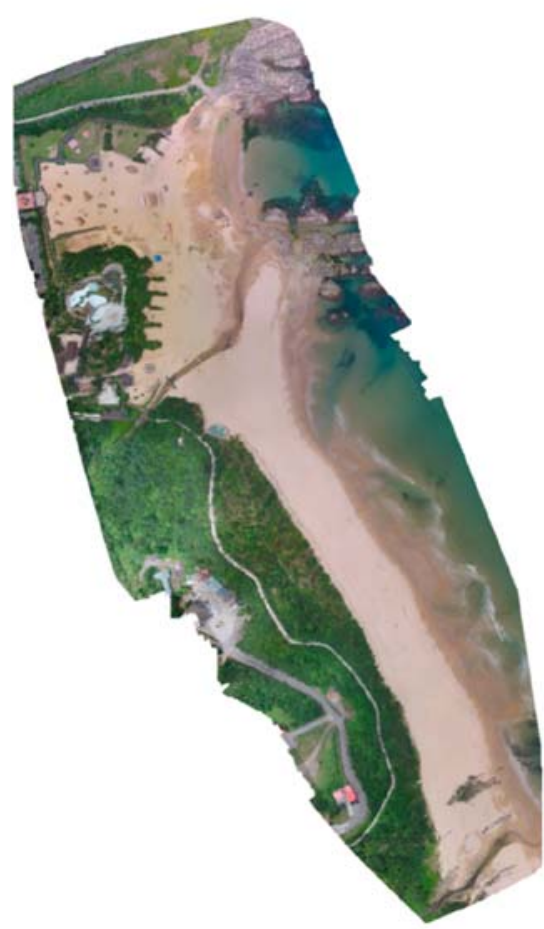

(a) Orthophoto of Yanliao Beach

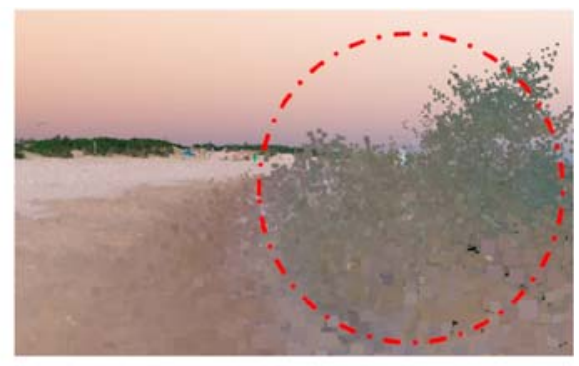

(b) Distribution of ill-matching points

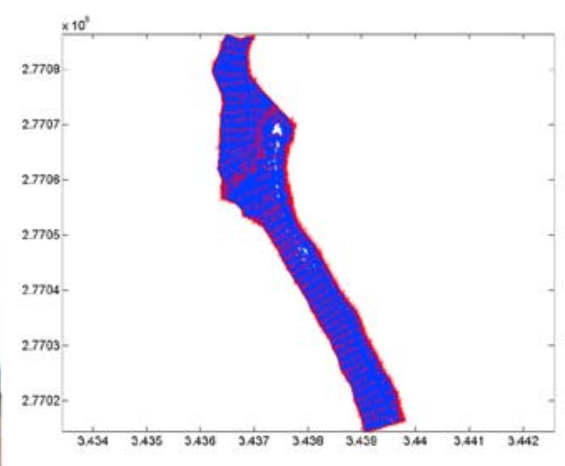

(c) Analysis region, including a baseline and a $0-\mathrm{m}$ contour line

Fig. 13. Definition of region in the sandy beach area for further analysis. 


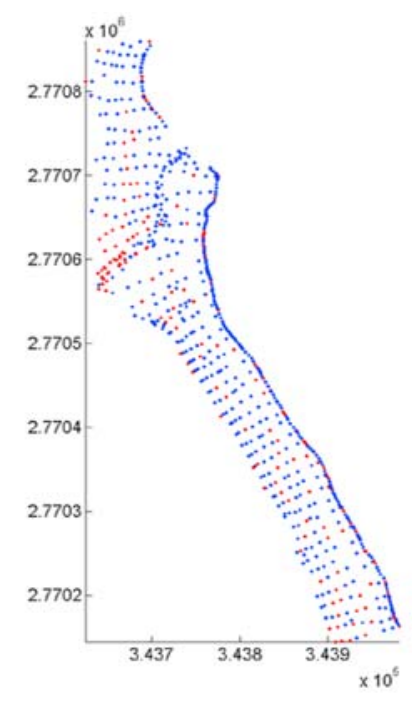

(a) Reference topography points

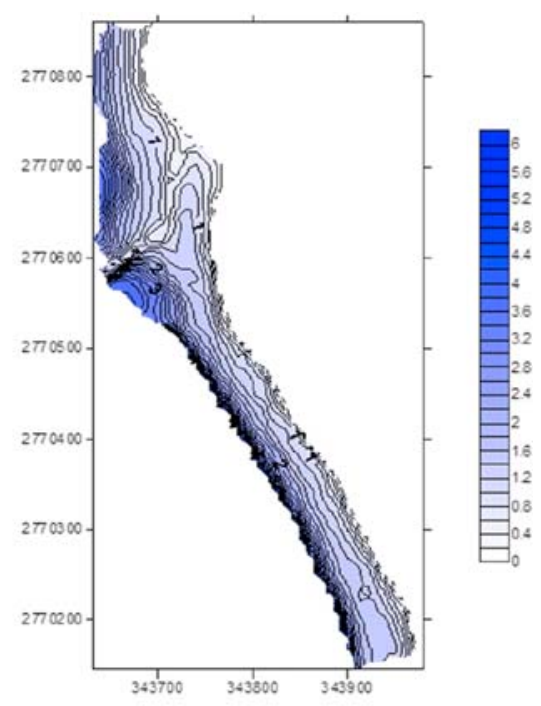

(b) Reference contour map

Fig. 14. Reference contour map interpolated using 752 points.

the $95 \%$ confidence interval for the normal distribution statistics was set as the range of allowable errors to manage the outliers. The allowable error range was limited to $\mu \pm 2 \sigma$. Data points with errors that exceeded the allowable error range were marked with a circle and represented as blunder points (Fig. 17). Pearson product-moment correlation coefficients were used to investigate the linear relationship. Figure 18 shows that the correlation coefficients at the operational altitudes of 70 and $100 \mathrm{~m}$ are 0.990 and 0.989 , respectively, which indicate strong correlations. In this figure, most of the blunder points are distributed in the elevation range of $0.0-2.0 \mathrm{~m}$, and the maximum elevation difference in the UAV topography obtained from the images captured at the flight altitude of $70 \mathrm{~m}$ is $1 \mathrm{~m}$, which is larger than that in the topography obtained from the images captured at the UAV flight of $100 \mathrm{~m}$. Moreover, most of the blunder points occur in the nearshoreline and steep-slope areas, according to results shown in Fig. 17.

\subsection{Comparison with results obtained using a laser scanner}

To investigate the differences between the accuracies of auxiliary observations on the homogeneous and steep-slope areas of Yanliao Beach, a region of the beach with both features was selected (Fig. 19(a)). According to the configuration, GCPs were arranged at the four corners and the center of the experimental area. A LIDAR scanner (Fig. 19(b)) was used on three sides of the steep-slope area to scan the topographic elevations along different directions to reduce the point cloud vacancies due to object obstruction. Lateral (gimbal camera) shooting and a higher image-overlap rate were added in the flying course planning to facilitate auxiliary observations (Table 6 and Fig. 20). In Case 1, the following parameters were used: operational altitude: $70 \mathrm{~m}$, gimbal camera angle: $80^{\circ}$, end lap overlap rate: $80 \%$, side lap overlap rate: $30 \%$, and flying course: double-S design. In Case 2, a photo-capturing direction with an angle of $40^{\circ}$ was incorporated into the shooting schedule, and the shooting direction was fixed along the steep-slope area. In Case 3, the end and side lap rates were set to $90 \%$ and $50 \%$, respectively. The number of point clouds acquired using the LIDAR scanner should generally be lower than the GSD $(3.2 \mathrm{~cm})$ of the UAV images captured at the operational altitude of $70 \mathrm{~m}$. Therefore, the horizontal and vertical intervals were set to $3 \times 3 \mathrm{~cm}^{2}$ for obtaining the point clouds of the reference topography.

The results of Case 1, 2, and 3 and LIDAR measurements were imported into the Pix4Dmapper application to generate point cloud data (Fig. 21) and contour maps for presenting the derived topography results (Fig. 22). The area along the $1.5-\mathrm{m}$ contour line was fragmented in the point-cloudmatching UAV images, which indicated that image matching in the homogeneous region was inaccurate. To investigate the difference between the elevation distributions generated using the LIDAR point clouds of the reference topography and those generated using the settings in different cases, two 


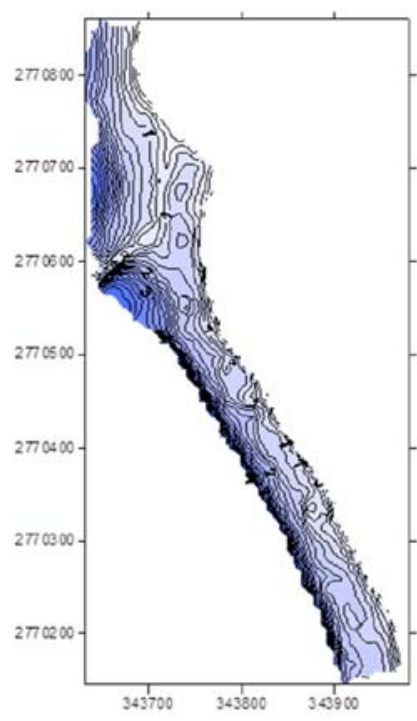

(a) UAV contour result at the operational altitude of $70 \mathrm{~m}$

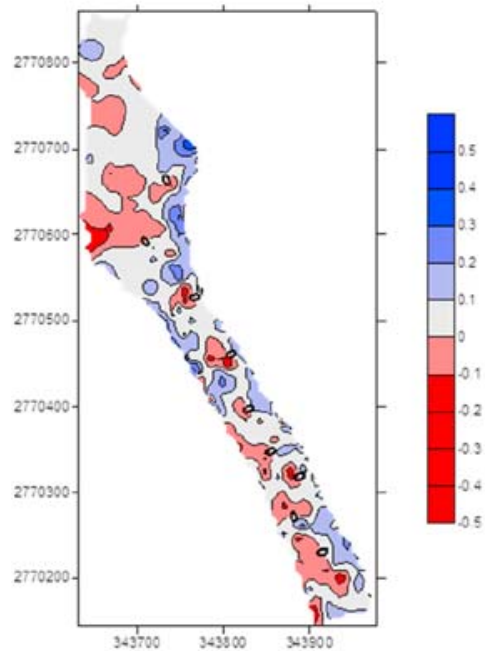

(c) Difference in elevation distribution between the reference topography and the topography obtained using the UAV at the operational altitude of $70 \mathrm{~m}$

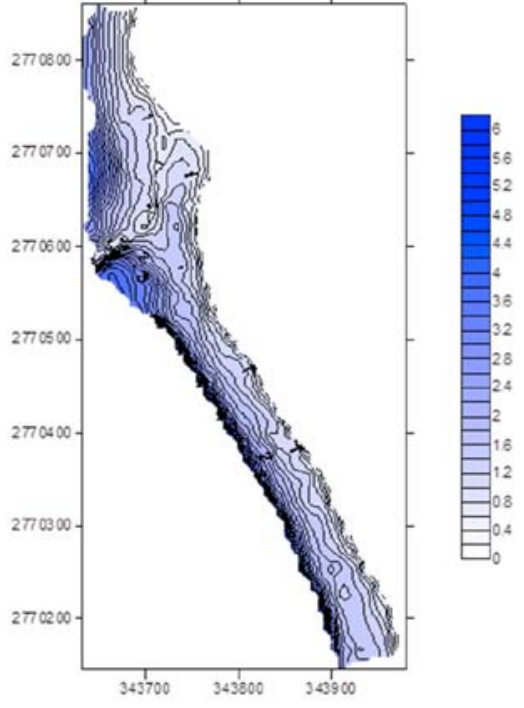

(b) UAV contour result at the operational altitude of $100 \mathrm{~m}$

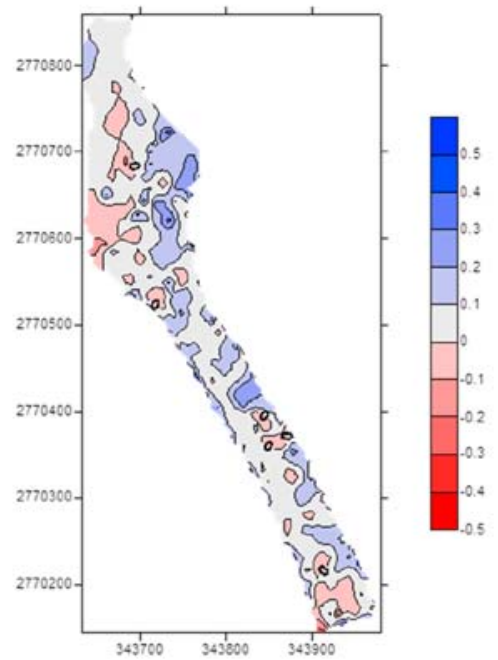

(d) Difference in elevation distribution between the reference topography and the topography obtained using the UAV at the operational altitude of $100 \mathrm{~m}$

Fig. 15. UAV contour results and elevation difference distributions.

types of topographic maps were inlaid (Fig. 23). Compared with the elevation difference distributions in other two cases (Case 1 and 3), the elevation difference distribution in Case 2 was substantially reduced because tilt UAV photographs of the steepslope area were included in the computation. Six equally spaced sections were plotted at identical intervals on the topographic maps of LIDAR, Case 1, 2 , and 3 to compare the elevation differences (Fig. 24). For the elevation range of $2-4 \mathrm{~m}$ in the steep-slope area, the elevation distributions measured in Case 1, 2, and 3 were consistent with the reference topography measured using LIDAR. The elevation ranged from 1 to $1.8 \mathrm{~m}$ in sections $\mathrm{S} 1$, 


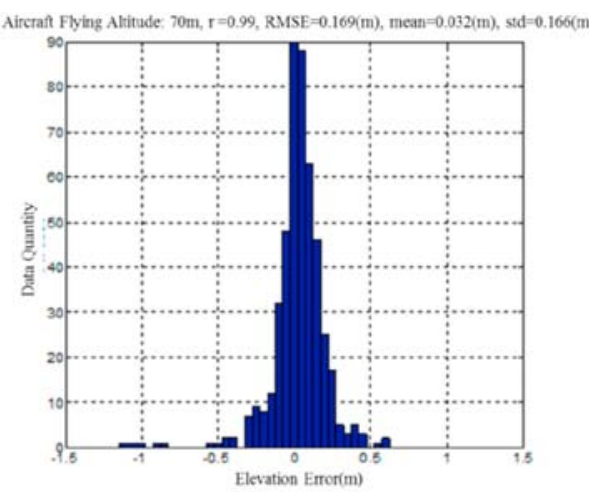

(a) $70 \mathrm{~m}$

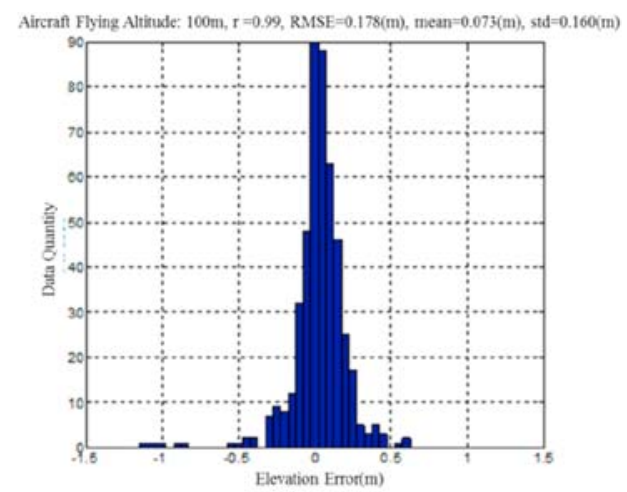

(b) $100 \mathrm{~m}$

Fig. 16. Elevation error distribution at two flight altitudes.

Table 5. Statistics of four accuracy indicators for two UAV image topographies

\begin{tabular}{llllr}
\hline Altitude $(\mathrm{m})$ & Mean error $\mu(\mathrm{m})$ & Standard deviation $\sigma(\mathrm{m})$ & RMSE $(\mathrm{m})$ & \multicolumn{2}{c}{$\begin{array}{l}\text { Allowable error }(\mu \pm 2 \sigma) \\
(\mathrm{m})\end{array}$} & $\begin{array}{ll}\text { Min. } \\
\end{array}$ \\
& & & & Max. \\
\hline 70 & 0.032 & 0.166 & 0.169 & -0.299 \\
100 & 0.073 & 0.160 & 0.176 & -0.246 \\
\hline
\end{tabular}

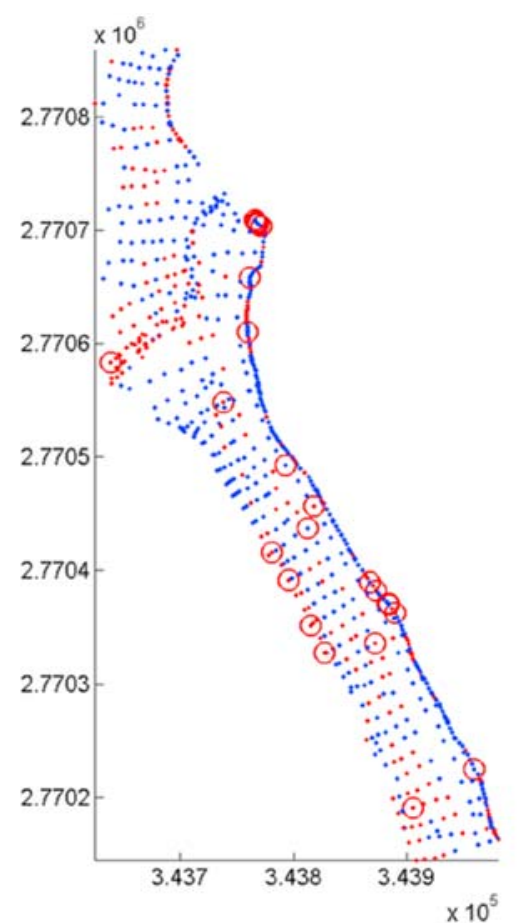

(a) Twenty-six blunder points distributed in the result obtained at the UAV flight altitude of $70 \mathrm{~m}$

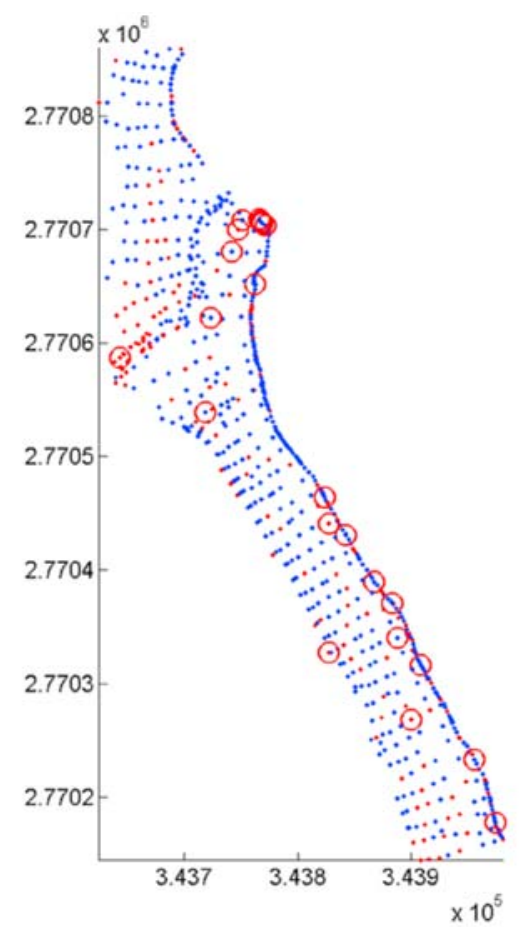

(b) Twenty-five blunder points distributed in the result obtained at the UAV flight altitude of $100 \mathrm{~m}$

Fig. 17. Data points with gross error in UAV image topography. 


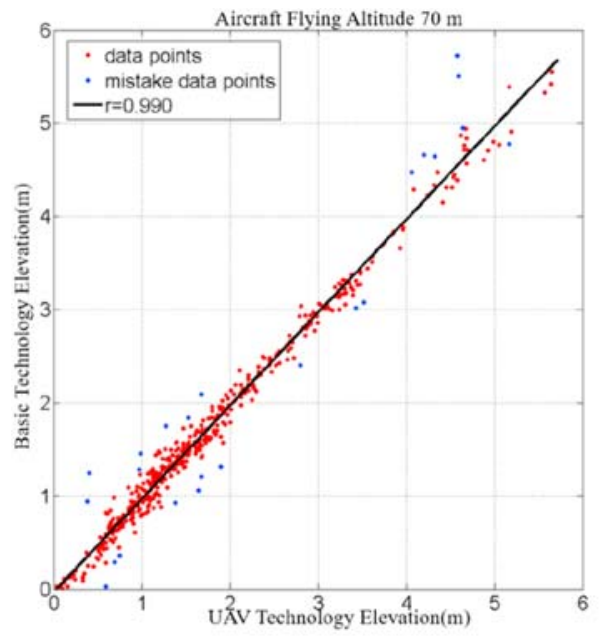

(a) $70 \mathrm{~m}$

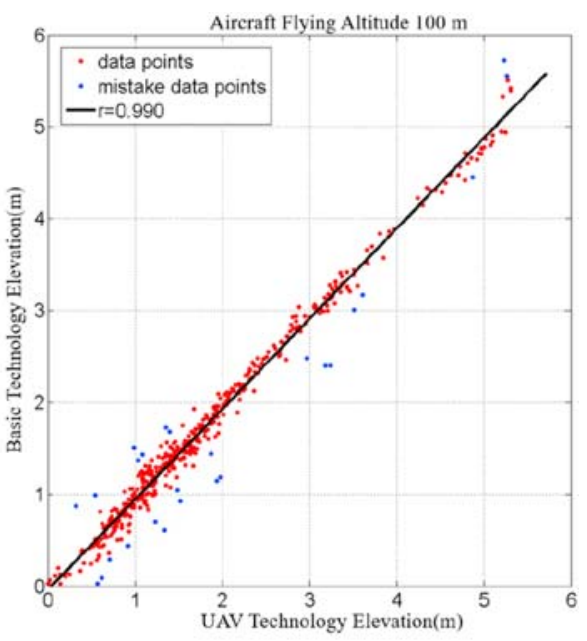

(b) $100 \mathrm{~m}$

Fig. 18. Distribution of Pearson product-moment correlation coefficient at two operational altitudes.

S2, and S3 for Case 1, 2, and 3. The elevation distribution was irregular and inconsistent because the UAV image matching was inaccurate. For Case 1 and 3 , although the overlap rate increased from $80 \%$ to $90 \%$, the problem of inaccurate image matching was unsolved. The elevation ranged from 1 to $1.8 \mathrm{~m}$ in section S4, S5, and S6 for Case 1, 2, and 3. The overall elevation errors in the topographies obtained using UAV imaging were smaller than that of the reference topography.

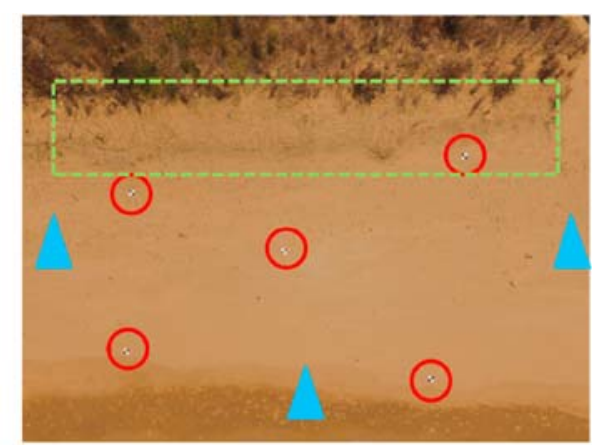

(a) Distribution of GCPs for UAV and setup stations as determined using a laser scanner

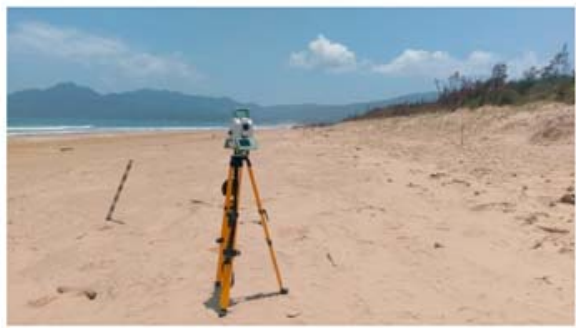

(b) Laser scanner used in this study

Fig. 19. Configuration of auxiliary observation.
The measurement errors were analyzed in terms of statistical indicators-mean error, standard deviation, RMSE, and Pearson product-moment correlation coefficient-to compare the reference topography obtained using a LIDAR scanner and the topographies obtained using UAV image matching. The statistical results of each accuracy indicator were computed and are presented in Table 7 and Figs. 25-27. The mean errors in Case 1, 2, and 3 were $-0.049,-0.058$, and -0.063 , respectively, and the corresponding standard deviations were 0.106 , 0.088 , and 0.102 . The results of the UAV image measurement, which were consistent with the results obtained in the previous section, indicated that a few of the elevation measurements were lower than the corresponding elevations in the reference topography. Standard deviation represents data dispersion. Moreover, the smaller standard deviation of Case 2 revealed that the incorporation of lateral shooting increased the mapping accuracy than those in Case 1 and 3. The RMSEs of Case 1, 2, and 3 were $0.116,0.106$, and $0.119 \mathrm{~m}$, respectively. These values indicated that the RMSE of Case 2, in

Table 6. Planning of flying course for auxiliary observation

\begin{tabular}{lllll}
\hline Item & & Case-1 & Case-2 & Case-3 \\
\hline \multicolumn{2}{l}{ Angle of camera (deg) } & 80 & 80 & 80 \\
& & & +45 & \\
Overlap rate (\%) & End lap & 80 & & 90 \\
& Side lap & 30 & & 50 \\
Route type & & Double S & & \\
No. of photos & 59 & 72 & 96 \\
Time (min) & 2 & 3 & 4 \\
GSD $(\mathrm{cm})$ & 3.14 & 3.08 & 3.14 \\
\hline
\end{tabular}

*Limit UAV operational altitude to $70 \mathrm{~m}$. 


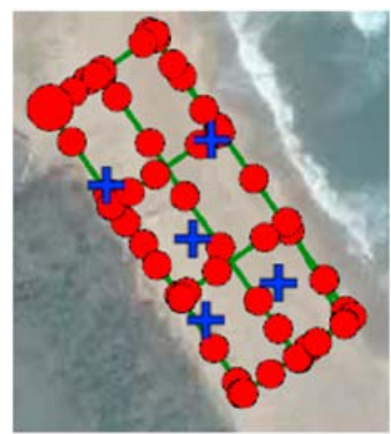

Case 1

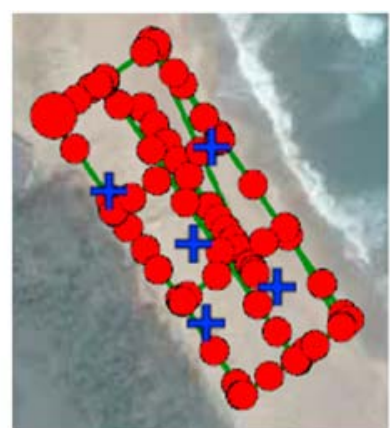

Case 2

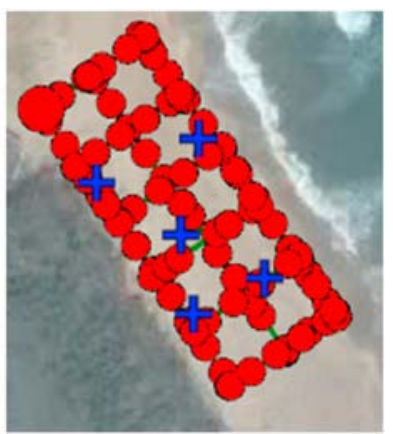

Case 3

Fig. 20. Actual flying courses for auxiliary observation.

which lateral shooting was employed, was lower than those of Case 1 and 3. The difference between the RMSEs of Case 1 and 3 was only $0.003 \mathrm{~m}$, which indicated that an increase in the image-overlap rate did not significantly increase the measurement accuracy. A 95\% confidence interval was employed in the normal distribution to explore the points that caused excessively large errors for use as the allowable error range, and the allowable error range was limited to the mean error of $\pm 2 \sigma$. The

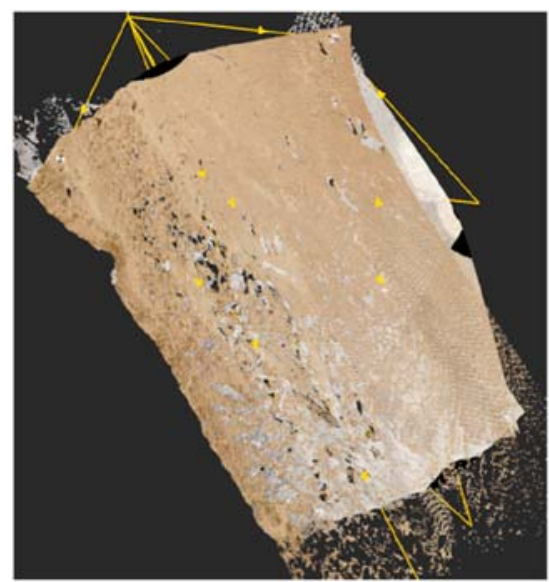

(a) LIDAR scanner result

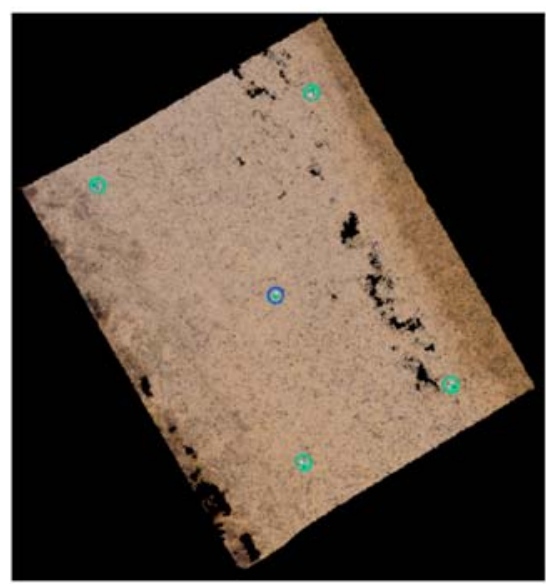

(c) Case 2

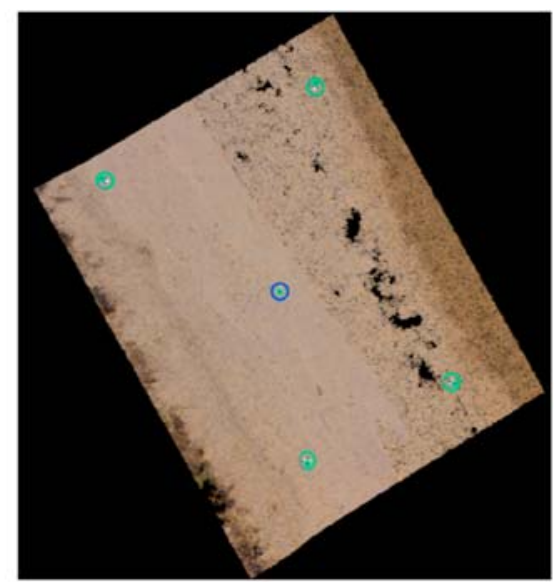

(b) Case 1

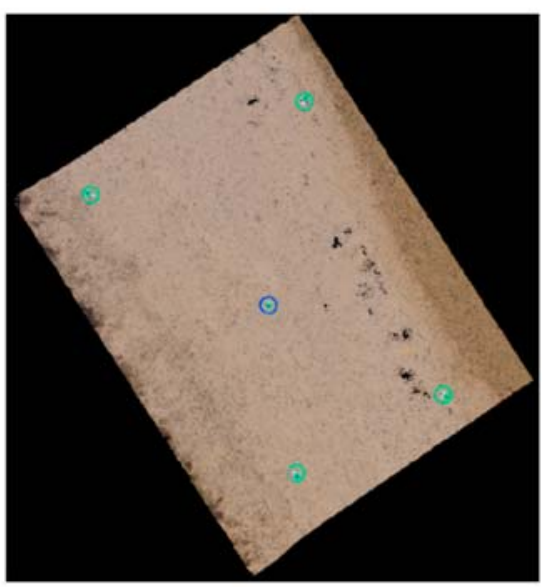

(d) Case 3

Fig. 21. Point clouds obtained with different experimental setups. 


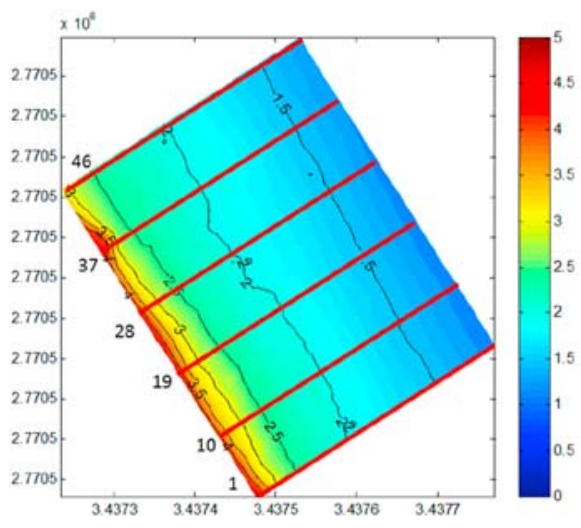

(a) LIDAR scanner result

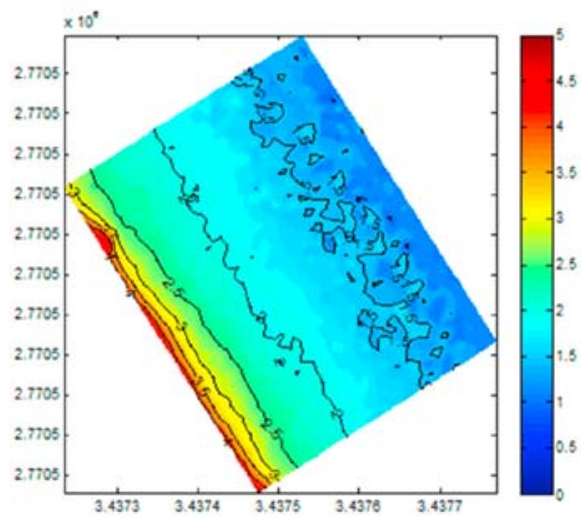

(c) Case 2

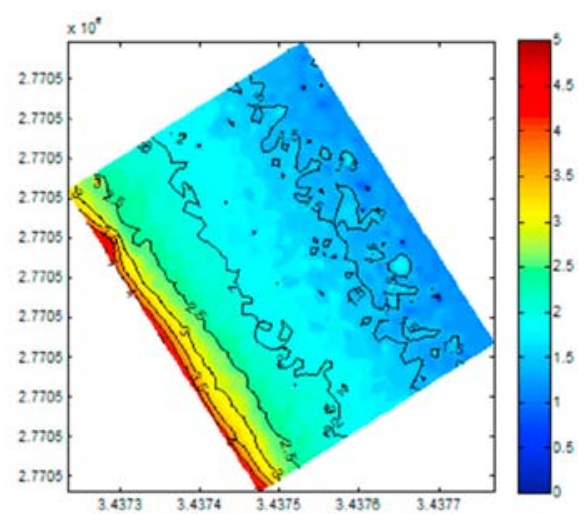

(b) Case 1

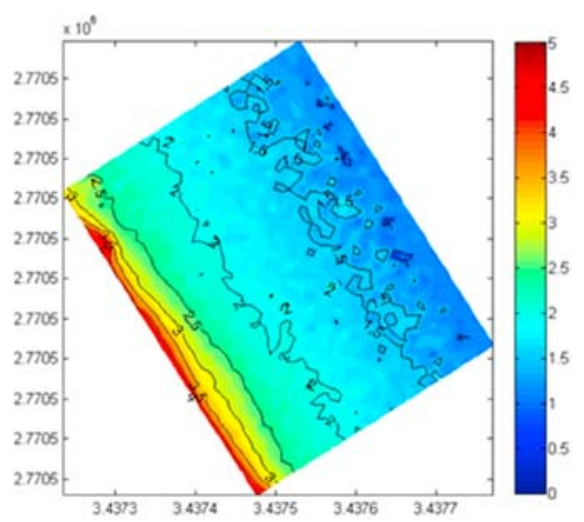

(d) Case 3

Fig. 22. Contour maps derived using different setups.

correlations between the elevation of the reference topography and the elevations obtained using UAV imagery in Case 1, 2, and 3 were 0.988, 0.991, and 0.989 , respectively (Figs. 25-27). These values indicate a high level of correlation. Numerous outliers were found in the distribution maps in the elevation range of 1-1.8 $\mathrm{m}$-consistent with the aforementioned test area that exhibited inaccurate image matching.
This section explores the difference between the mean errors in elevation in the reference topographies obtained using the TS and a LIDAR scanner. The comparison results revealed that the mean error values in the UAV image topographies computed using a TS and a LIDAR were positive and negative, respectively. In practical applications, the TS measures elevation by using the signals reflected by a survey prism affixed to a pole. The pole

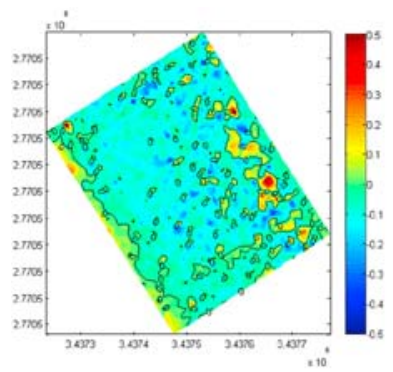

(a) Lidar_DSM-UAV_DSMI

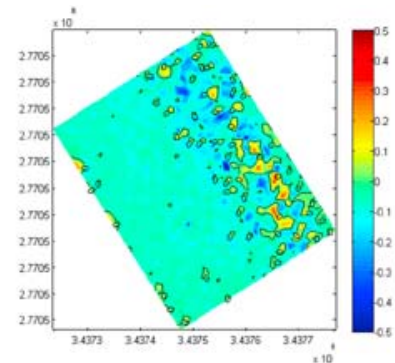

(b) Lidar DSM-UAV_DSM2

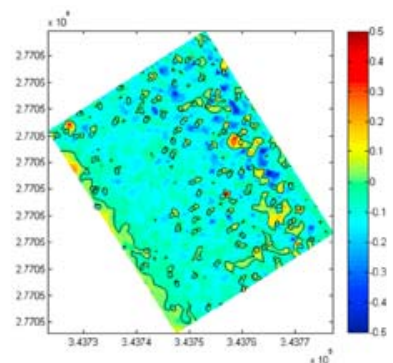

(c) Lidar DSM-UAV DSM3

Fig. 23. Color rendering for DSM difference results of (a) Case 1, (b) Case 2, and (c) Case 3. 

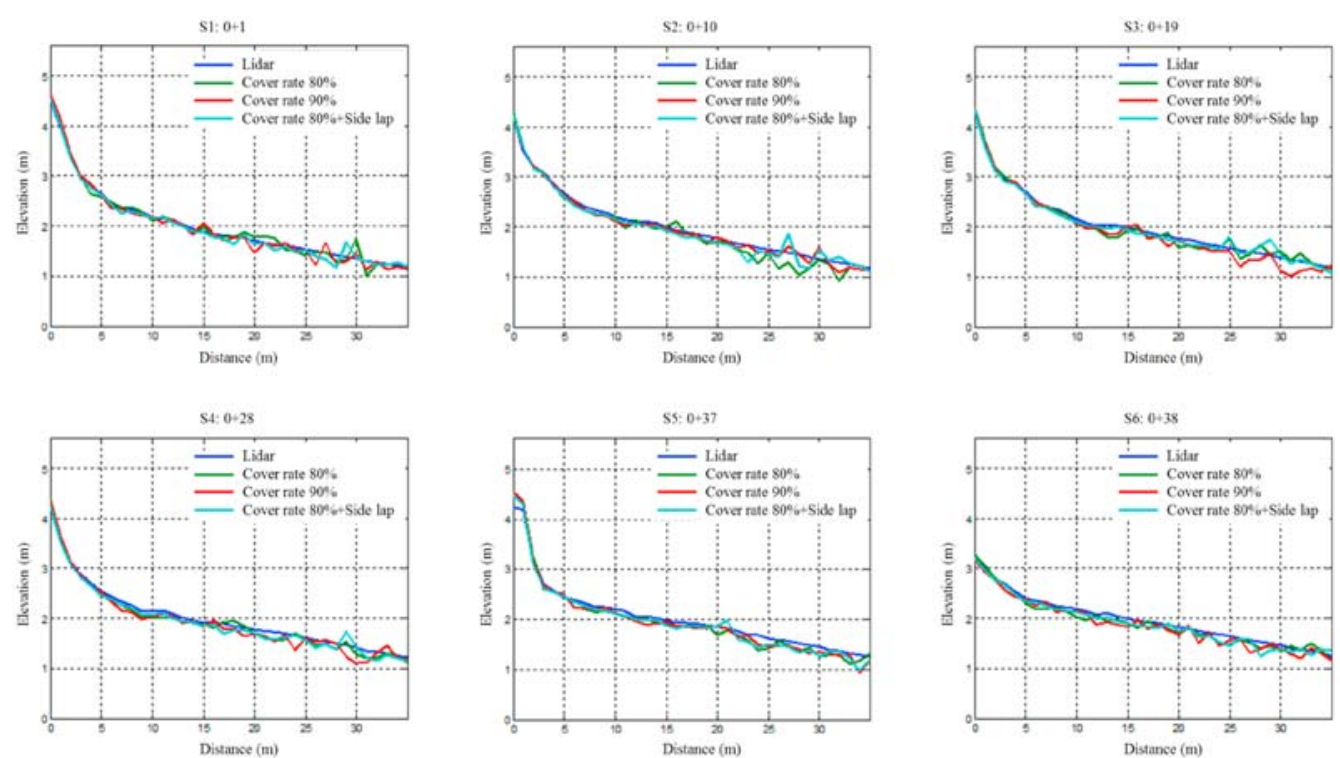

Fig. 24. Elevation profiles of sections S1-S6.

Table 7. Error indicators pertaining to elevations in different cases

\begin{tabular}{lllllll}
\hline Item & r-square & Mean error $(\mathrm{m})$ & Standard deviation $(\mathrm{m})$ & RMSE $(\mathrm{m})$ & GCP-RMSE (m) & $\begin{array}{l}\text { Allowable error } \\
(\mathrm{m})\end{array}$ \\
\cline { 4 - 7 } & & & & & Min. & Max. \\
\hline Case-1 & 0.988 & -0.049 & 0.106 & 0.116 & 0.011 & -0.259 \\
Case-2 & 0.991 & -0.058 & 0.088 & 0.106 & 0.008 & 0.162 \\
Case-3 & 0.989 & -0.063 & 0.102 & 0.119 & 0.007 & -0.236 \\
\hline
\end{tabular}

is inserted in the sand during measurement. The insertion depth of the prism pole can be $3-5 \mathrm{~cm}$. A LIDAR scanner measures elevation by emitting a laser beam toward a measurement point on a soil surface. Artificial and systematic errors, such as the errors due to control surveying or those introduced by measurement personnel, cause differences between the point heights measured using the two methods. Both LIDAR and UAV imagery are remote-sensing techniques that acquire data based on the surface characteristics of an object. The results of this study were presented as dense point clouds, and they were relatively consistent.
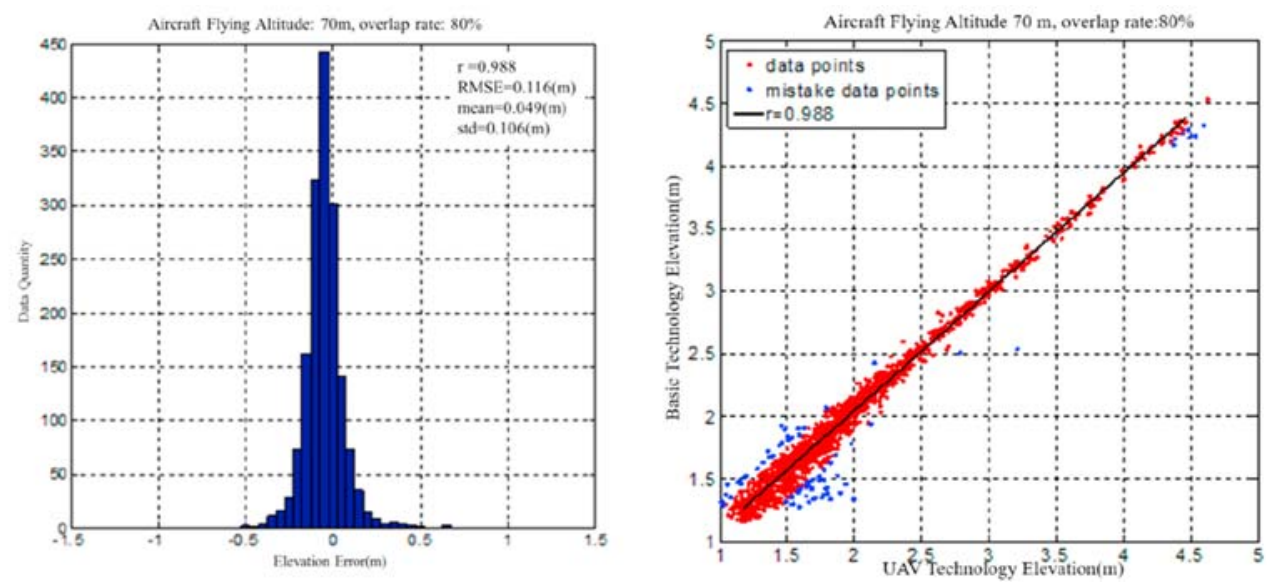

Fig. 25. Correlation and elevation error distribution in Case 1. 

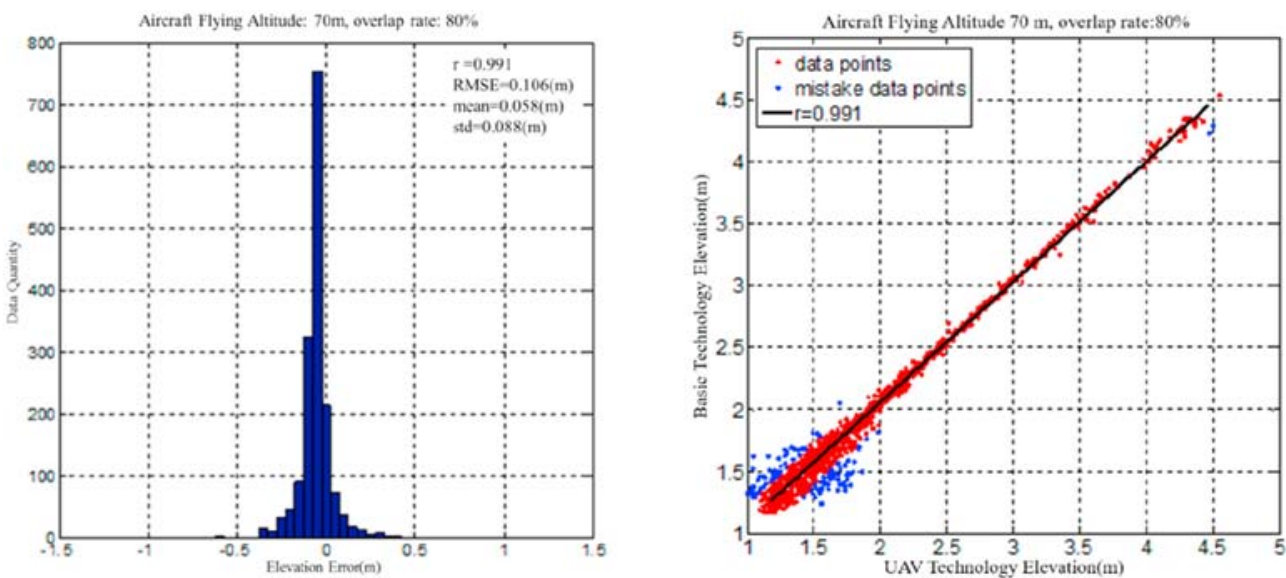

Fig. 26. Correlation and elevation error distribution in Case 2.
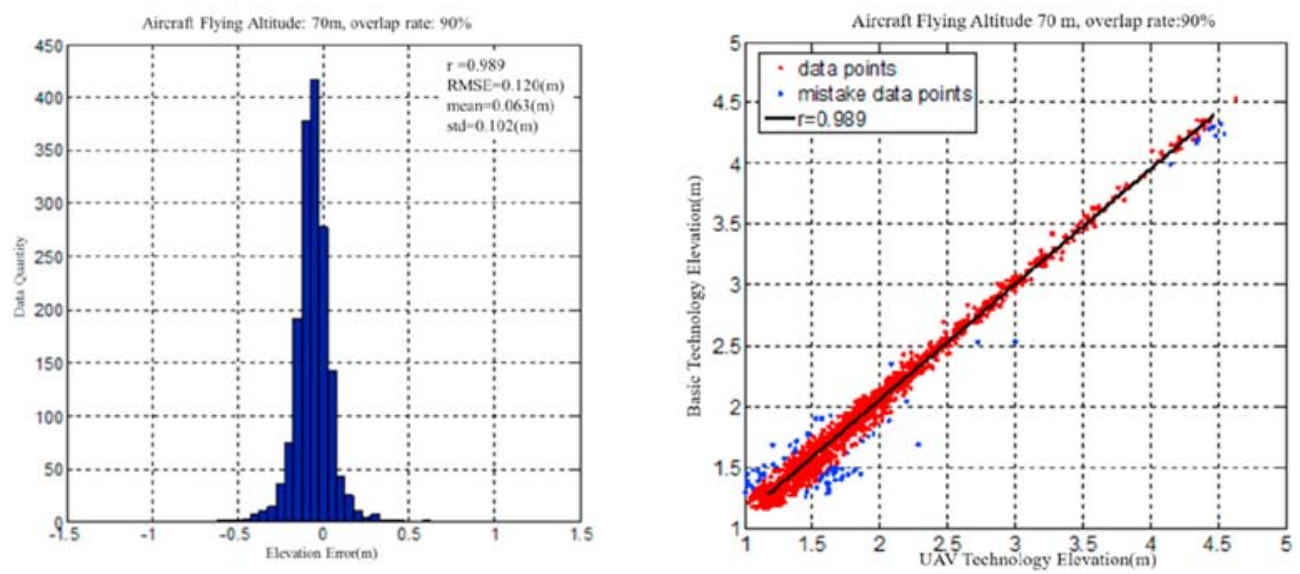

Fig. 27. Correlation and elevation error distribution in Case 3.

\section{Conclusion}

UAV imaging technology has various advantages, such as high portability, low operational altitude, and high mobility, and it can be used for monitoring and managing coastal areas. This technology was used in the present study to monitor beach topography. In situ data were acquired through a UAV-mounted non-metric camera and GCPs. Pix4Dmapper, a UAV image postprocessing software application, was used to identify the feature points to obtain the information pertaining to the overall change in sand topography. The method proposed in this study can reduce the amount of human resources required by conventional direct observation methods, in addition to reducing the indirect observation costs. The UAV, TS, and laser scanner used in this research cost approximately NT $\$ 45,000, \mathrm{NT} \$ 20,000-\mathrm{NT} \$ 100,000$, and NT $\$ 200,000-N T \$ 600,000$ (depending on the laser power), respectively.

The measurement configuration and flying course planning of this study included a double-S-type flying course, camera tilt angle of $-80^{\circ}$, an end lap overlap rate of $80 \%$, a side lap overlap rate of $30 \%$, UAV operational altitudes lower than $100 \mathrm{~m}$, and measured RMSEs of less than $20 \mathrm{~cm}$. Compared with the reference topography measured using the $\mathrm{TS}$, the topography measured using UAV imaging at the operational altitudes of 70 and $100 \mathrm{~m}$ exhibited RMSEs of 16.9 and $17.6 \mathrm{~cm}$, respectively. Compared with the reference topography that was measured using a LIDAR scanner, different photography conditions effectively increased the measurement accuracy to an RMSE of $10.6 \mathrm{~cm}$ when the measurement was conducted at the UAV operational altitude of $70 \mathrm{~m}$. However, gross errors were mostly generated from the data of land-sea boundary, steep-slope areas, and areas in which the beach feature points were inaccurately matched. The errors were considerably influenced by the waves at different times and the weather conditions at the time when the UAV image measurement system was used to estimate the $0-\mathrm{m}$ contour line. Thus, various inconsistencies were observed between the 
reference topography and the UAV imagery results. Moreover, the maximum error was up to $10 \mathrm{~m}$. If the UAV image topography contour of $0 \mathrm{~m}$ is used as a reference for coastline measurement in the future, the authors of this study suggest that UAV aerial photography should be performed when the ocean is quiet and the weather is breezy. UAV images should be captured when the tide level is the lowest in the day to reduce the effect of waves. Future studies can consider incorporating the coastline image monitoring system to determine an appropriate land-sea boundary to reduce the errors that influence UAV image measurements.

\section{Acknowledgement}

We are grateful to the participants of the research team. We thank the experts and scholars for reviewing, editing, and providing valuable comments on the manuscript.

\section{References}

[1] Casella E, Rovere A, Pedroncini A, Mucerino L, Casella M, Cusati AL, et al. Study of wave runup using numerical models and low-altitude aerial photogrammetry: a tool for coastal management. Estuar Coast Shelf Sci 2014;149:160-7.

[2] Casella E, Rovere A, Pedroncini A, Stark CP, Casella M, Ferrari $\mathrm{M}$, et al. Drones as tools for monitoring beach topography changes in the Ligurian Sea (NW Mediterranean). Geo Mar Lett 2016;36:151-63.

[3] Chiang S-P. UAV photogrammetry for beach topography surveying. Master Thesis. National Taiwan Ocean University, Department of Harbor and River Engineering; 2017.

[4] Drummond Christopher D, Mitchell D Harley, Turner Ian L, Matheen ANashwan A, Glamore William C. UAV applications to coastal engineering. In: Australasian Coasts \& Ports Conference; 2015. p. 15-8.
[5] Fang H-M, Hsiao S-S, Yang Y-C, Liao S-Y. Application of binocular stereo imaging for the beach topographic surveying. In: Proceeding of 36th Ocean Engineering Conference in Taiwan; 2014. p. 647-52 (in Chinese).

[6] Mancini Francesco, Dubbini Marco, Gattelli Mario, Stecchi Francesco, Fabbri Stefano, Gabbianelli Giovanni. Using unmanned aerial vehicles (UAV) for high-resolution reconstruction of topography: the structure from motion approach on coastal environments. Rem Sens 2013;5: 6880-98.

[7] Harwin S, Lucieer A. Assessing the accuracy of georeferenced point clouds produced viamulti-view stereopsis from unmanned aerial vehicle (UAV) imagery. Rem Sens 2012;4: 1573-99.

[8] Holland KT, Holman RA, Lippmann TC, Stanley J, Plant N. Practical use of video imagery in nearshore oceanographic field studies. IEEE J Ocean Eng 1997;22(1):81-92.

[9] Holman RA, Stanley J. The history and technical capabilities of Argus. Coast Eng 2007;54:477-91.

[10] Hsiao Y-H, Chen H-T, Chuang S-C, Huang M-C. Preliminary application of a Pan/tilt camera in coastal image Research. In: Proceeding of the 30th Ocean Engineering Conference in Taiwan; 2008. p. 745-50 (in Chinese).

[11] Hsu C-H, Lin W-H, Huang Y-T, Lin S-H, Lin C-J. "Research on technological innovation of topographic maps update maintenance," Ministry of the interior research project Report No. 103-301000100G002. 2014.

[12] Turner Ian L, Harley Mitchell D, Drummond Christopher D. UAVs for coastal surveying. Coast Eng 2016;114:19-24.

[13] Liao S-Y. Application of binocular stereo imaging for the beach topographic surveying. National Taiwan Ocean University, Department of Harbor and River Engineering; 2014. Master Thesis.

[14] National Land Surveying and Mapping Center, Ministry of the Interior, R.O.C.. Operation manual for encrypted control and Tugen measurement using virtual base station real-time dynamic positioning technology. 2010 (in Chinese).

[15] Plant NG, Holman RA. Intertidal beach profile estimation using video images. Mar Geol 1997;140:1-24.

[16] Rau J-Y, Chen C-Y, Jhan J-P, Liu K, Lee W. Accuracy analyses of UAV photogrammetry and direct georeferencing. Taiwan J Geoinf 2014;2(1):1-22.

[17] Su B-H, Hsiao Y-S, Wang J-M, Chen S-C. A feasibility study on unmanned aircraft systems for high accuracy mapping. J Chin Soil Water Conserv 2013:1-12. 